\title{
Agent-based Computational Economics: Methodology and Its Application in Electricity Market Research
}

\author{
Yu Shun-kun and Yuan Jia-hai
}

\begin{abstract}
The restructured electricity market is a complex adaptive system and worldwide experiences show that market design is a complicated task. Recently, under the paradigm of Agent-based computational economics (ACE) a new research focus is forming and a large number of literatures are springing up, but there is still no the discussion on ACE's theoretical value and insufficiency in the research of electricity market in the hierarchy of methodology, therefore the author's research is an attempt in this aspect. By means of analyzing the evolution of economics methodology from mathematical deduction to simulation induction and their inherent relevance, the unique superiority of ACE on the level of methodology is expounded. The further selective survey on existing literatures shows that with the ACE model the marketization process can be understood clearly in deeper level and wider scope. Finally to give a reference to theoretical progress, the prospect application of ACE, especially its potential in China's electric sector restructuring is discussed.
\end{abstract}

Index Terms-- Multi-agent systems; Computer simulation; Electric power system; Electricity market

\section{INTRODUCTION}

$\mathrm{T}$ HE electric power sectors around the world continue to evolve from regulated, vertically integrated monopoly structures to open markets that promote competition among suppliers and provide consumers with a choice of services. The unbundling of the generation, transmission, and distribution functions creates opportunities for many new players or agents to enter the market. As a result, fully functioning markets are distinguished by the presence of a large number of companies and players that are in direct competition and coordination. The start point of restructuring is that a more competitive and freer market can lead to increased economic efficiency expressed in higher quality services and products at lower retail prices [16]-[18].

Because of the role in national economy, the long historical traditions and the uniqueness technology characteristics of

$\mathrm{Yu}$ shun-kun is with Business school, North China Electric Power University, Changping District, Beijing China 102206(e-mail: ysk21@sina.com)

Yuan Jia-hai is with Business school, North China Electric Power University, Changping District, Beijing China 102206(e-mail: yuanjh126@126.com) electric power sector the transition to market is kind of intricate phenomena. It is in this that the advancement of market-oriented reforms is handicapped around the world. Though according to basic economics theory market-oriented restructuring will gain in social welfare different interest groups benefit differently and have totally different judgments. Whether it be decisions on market structure or market rules, the essence of the restructuring is the establishment of new 'rules for game'. According to F.V. Hayek institutions are not 'designed' by few but 'found' by all unconsciously [12]. So it is important to collect as much opinion from all sides as possible when designing the market. Nonetheless for electricity market to operate we must first have a set of market rules. Since the design of market rules is the definitions of participator's right and duty, we must be very cautious to the robustness and reliability of market rules. Otherwise disastrous results can incur.

The restructured electricity market is a complex adaptive system consisting of multiple competing generators, consumers and other participators. Every market participator has its own business strategy, risk preference and decision model and makes decision autonomously under certain market structure and trading rules. More importantly, all the economic agents have learning ability to adapt and change their behaviors according to payoffs in the market.

The complexities of electricity market make it difficult for mathematics or experimental tools to properly analyze the inner regularity of electricity market. Though successful experiences in England and Wales and some states in United States can help with market design in other regions, each electric power system has its own technological and social features so each has its own details for attention and successful experiences in one country cannot be taken for granted to apply in another regions.

Agent computation economics (ACE) is the computational study of economies modeled as evolving systems of autonomous interacting agents with learning capabilities, which is Specialization of economics research under the basic complex adaptive systems paradigm [1]-[2], [14]. As a fast growing new branch of economics that focuses mainly on understanding complex phenomena in economy, there are lots 
of applications in electricity market researches [3]-[7], [14], [19]-[21]. To illustrate why ACE is appropriate to analyze electricity market, the paper take pains to discuss the background of ACE, its methodology and its relation with other economics methodology. Then the paper overviews a selective literature and proposes for ACE's potential research in electricity market. The potential of its application in analyzing China's market restructuring and the key point that should be cautious is also proposed in the paper.

\section{BACKGROUND OF ACE}

\section{A. The skeleton of economics thinking}

\section{Methodology of mainstream economics}

The $20^{\text {th }}$ century is the century for economics to be axiomized and formalized. In order for economics gain the status of "science", economists introduce plenty of mathematics into the research of economics. However mathematics tool has its shortcoming. In order for mathematics tool to be appropriate the assumptions in the bottom layer are rather rigid. For example, the human is fully rational and profit-maximizer, the information is complete and perfect etc.

Since $50^{\text {th }}$ of last century, game theory has come to the attention of economists. Since then economists have tried to re-construct the microeconomics by applying game theoretic analysis. However it is soon noticed that in game model the assumption about individual is as rigid as, if not more rigid than that in general equilibrium. That is, in game theory the assumptions on individual are not realistic at all. So even game theory provides a tool for analyzing interactions between individual's decision the problem of how to utilize this tool has long be puzzled the economists.

\section{Methodology of experimental economics}

The methodology of mainstream economics featured by mathematics deduction establishes perfect economics theories, but unfortunately these theories cannot guide human's economic practices. The evolution of economy system is determined by the interactions among participators, not by externally constrained equilibrium conditions. So naturally the methodology of economics research comes from deduction to induction, which is the start point of experimental economics. Concretely, it is to research how subjects response to given environments and institution structures. Then economics theory or policy suggestions are proposed based on induction.

Along the path, economists carry through a lot of experiment researches [2]. However, the method of experiment has its own limitations. First of all, it cannot be guaranteed that the true psychology of human subjects be observed under experimental situations. Second, the experimental environment may differentiate with true situation. Obviously under different environments the psychology and behavior of subject is different. Meanwhile constrained by objective conditions, only short-term behaviors can be observed. Also under many situations experiments cannot be carried through at all. So it is obvious that although experiment economics devotes to establish theory on the true human behavior this methodology is rather limited.

\section{B. Complexity in economy}

The decentralized market is a complex system consisted of heterogeneous agents featured as follows:

$>$ Large numbers of economic agents involved in distributed local interactions.

$>$ Local interactions give rise to global regularities.

$>$ Global regularities feed back into local interactions.

$>$ And two-way feedback between micro and macro structure mediated by evolving agent interaction network $[1,13]$.

The restructured electricity market possesses all the characteristics above. In the operation of electricity market, the generation companies distribution companies and consumers adjust their behaviors and strategies according to their payoff in the market activities. On the same time, the strategic behaviors of market participators influence the market rules and structures bottom-up. The regulator cannot directly dictate order to participators and can only adjust the rules according the market performance.

Mainstream economics obviates complexity in economics by rigid assumptions. However for a deeper understanding of economics we must tackle complexity directly. Introduction complexity into economics challenges the mainstream framework of economics analysis.

\section{Advances in Artificial Intelligence (AI)}

Distributed Artificial Intelligence (DAI) is the sub-field of AI that aims to solve problems by decomposing problems into sub-problems and get them resolved by different agents or programs, then the problem is resolved by the alliance of individual agent. On the domain of DAI, the interaction and coordination between agents is one of the key focuses. People soon notice that when each agent represents an individual or organization, the technology of interactive multi-agent system can be used to simulate the social and economic phenomena, for example the early researches on Artificial Stock Market in Santa Fe Institute.

\section{Methodology Of ACE}

The method of mathematics modeling cannot capture the complexity in economy system. Experimental method has its own limitation. The advances in AI remind human to resort to computer modeling and simulation to research on complex phenomena in economy system. Under such background, agent-based computational economics is proposed.

Leigh Tesfatsion defines it as: "Agent computation economics $(A C E)$ is the computational study of economies modeled as evolving systems of autonomous interacting agents 
with learning capabilities"'[1], [14]. Epstein and Axtell take $\mathrm{ACE}$ as kind of generative science: "Growing economy from bottom up"[13]. ACE is specialization to economics of the basic complex adaptive systems paradigm. As a fast growing branch of economics research, the prime purpose is descriptive, to explain the complex phenomena in economy system; and the second one is normative, to construct theory based on deeper understanding of complexity in economy and guide the economic practice in real world. Compared with mainstream methodology that relies on externally constrained equilibrium, ACE researches macro-micro regularity and evolution in economy by bottom-up interactions among economic agents.

\section{A. Some key conceptions}

\section{Agent and multi-agent system}

While there is no generally accepted definition, in agentbased computational economics the concept of agent is referred to as piece of soft or program that can autonomously fulfill certain tasks in certain environment. The point of this conception is reactivity, autonomy, pro-activity and socialability [8]-[9]. Multi-agent system is a system consisted of more than one interactive agents populated in a common environment. We can get a plain analogy like that: in an agentbased simulation electricity market, the agents are the generators, distributors, ISO, regulator and customers, etc., and organized under certain rules. The interactive multi-agent system is the foundation of agent-based computational economics.

\section{Computational laboratory}

Here computational laboratory is the computer system framework to explore the interactions among multi-agents. There are now certain such frameworks available, such as Repast $^{\odot}$ and Swarm ${ }^{\odot}$, which generally are modularized and extensible and can be adjusted by experienced user with programming ability. The computational laboratory is the main tool of agent-based computational economics.

\section{Culture-dish experiment}

As chemists do chemical experiment when they get the recipe they mix the chemical and then let them react and observe the reaction aside. In agent-based computational economics, when researcher defines the original conditions of the "virtual world", the world then evolves over time solely driven by agent-agent interactions and without further outside intervention [1], [14].

\section{B. Method of agent-based computational economics}

The method of agent-based computational economics can be summarized as below [1], [14]:

$>$ Firstly the research defines the problem to resolve.

$>\quad$ Then researcher constructs a virtual economic world with groups of agents.

$>$ Modeler sets initial conditions of the world, cf. the trading rules of the world, the attributes and learning model of the agents, which is the preconditions of the experiment.

$>$ Modeler then let the world then evolves over time without further outside intervention.

$>$ Finally the researcher explains the data generated according to economics principle or proposes policy suggestions to guide practices.

\section{Relation with other economics method}

As a new branch of economics research, ACE must cooperate with other economics methodology.

Firstly, it must combine with mathematics deduction. It is because the complexity in economy that mathematics cannot deal with, but that does not mean that we should abandon mathematics. In fact the preliminary assumption and analysis of simulation results must be expressed in mathematics way.

ACE must combine with experimental economics. In fact it is because the limitation of experimental economics in doing real social experiment we need ACE to do thought experiment by way of simulation in computer model. And when defining the preliminary conditions of the virtual world, we should try to make the character of the agents as much similar as it can to the agents in real world. So the experimental methodology is needed in modeling. When explaining the data from running the model, we should be cautious and when condition is promised the parallel experiments between real and virtual world is necessary. Here we emphasize that while it is not necessary, also impossible for the model to be isomorphic with the real world it is necessarily homeostasis of the real world that captures the salient aspects of it.

Form the above we conclude that ACE is a natural way to deal with complexity and is complementary to other economics methods.

\section{ApPliCAtions Of ACE In ELECTRIC MARKET RESEARCH}

\section{A. Overview of selective literature}

Because the complexity of electricity market and the advantages of ACE relative to other economics methodology, many researchers take ACE to analyze some topics on electricity market. In this section we briefly overview related literature.

Professor Leigh Tesfatsion et al at Iowa State University of United States test the market power and efficiency in a computational electricity market with discriminatory doubleauction pricing [15]. The learning algorithm of agents in the model is modified Roth-Erev algorithm [10]. In a recent research project she tests the reliability of FERC's Wholesale Power Market Platform [19].

Professor Derek Bunn et al at London Business School develop a model of wholesale electricity market based on multi-agent system and use the model to simulate and analyze whether Pool or bilateral trading model should be adopted in England and Wales electricity market. Later they test NETA 
with their model [3]-[5]. In their model, the learning model of agents is modified GA. Further they utilize their model to analyze the EU electricity market, especially undertake a simulation analysis on reform strategy of Germany electric industry [6].

Chris et al at Hong Kong University research on multilateral trading theory in electricity market based on multi-agent model [7]. T Nagata et al in Japan research on the problem of units optimizing combination under the condition of electricity market [21].

The Argonne national laboratory of USA develops an agent-based model, Electricity Market Complex Adaptive Systems (EMCAS)[20]. By now it is the most realistic simulation model of electricity market. In the model, time horizon ranging from hours to decades is considered, which is necessary to understand the complex operation of electricity marketplaces. Both the spot and future market are considered so the decisions of Generation Company are very complex. In order for the decisions of Generation Company to be more realistic, empirical study is done to define the characteristics of Generation Company. The most outstanding feature of the model is that it considers the technology and economics aspects of electric power system simultaneously, which is a great advancement relative to prior researches.

Though a complete overview of current research is impossible, it is obvious that ACE is a promising tool for electric market research.

\section{$B$. The benefit of ACE model of electricity market}

By a careful journey along economics methodologies, it is evident that pure theoretic game model cannot provide adequate insight into electricity market because too many important details, when omitted in the model, may give rise to different conclusions. Experimental method, which can help gain insight into the psychology and behavior of market participators is useful but cannot provide a dynamics and overall picture of market process.

With the help of experimental method, centered on analyzing interactions among market participators, agentbased economics allows better insight into the processes and the results of strategic decisions in the power sector. As the section above indicated, the paradigm of multi-agent systems is well suited for the design and the implementation of simulation for complex systems. Deregulated electricity market can be modeled using ACE in a neat way. Of course such a simulation system has to be calibrated and validated using past data from empirical investigation. After this realistic setup of the system, future decisions can be simulated and their market outcome can be compared. Also ACE can consider economics concerns without omitting the sophisticated technological aspects of electric power system, which offers great opportunity for deep insight into electric market and is a great advance relative to traditional economics methodology.

The existing literatures show that agent-based computational economics can be used as acting recommendations for strategic decisions of certain participants as well as political decision makers. By considering the technology and economic aspects simultaneously, it can tackle with the complicated problems in electricity market without too much reduction. With different experiment designs we can test the propositions from all sides related with market design, which can help resolve the debates and clarify complex questions.

\section{Potential application of ACE to electric market deregulation in China}

China's electric power sector is undergoing market-oriented reform as that already happened in United Kingdom and some states of United States. The electricity market has not been established and the market rules are under design process. As China is a fast growing developing country and needs proper long-term investment on power system in the future so the main concerns of China are not only to raise the efficiency of the sector and improve service quality, but also to provide correct market signal for investors. For the uniqueness of China it is urgently need for some theory guidance that suits to China's situation. So the government is very cautious and the process to market slowly. To reduce the risks in market reform simulation methods should be applied to the study of market evolution and to the evaluation of market rule arrangement. We believe that ACE will play an important role in the research.

\section{PRospects AND CONCLUSIONS}

The existing literatures on electricity market mainly focus on test of market rules, analysis of market performance and market operation optimization. They typically are centered on the relationship between given market structure, firm behavior and market performance. A potential research focus, which is important for future's electric power sector policy and regulation, is to analyze the connection of electric sector with other energy related markets and the inner structure of electricity market to get insight into the evolution of industrial organization.

We also notice that ACE itself as a new branch of economics is rather young, if not in its infancy. The learning ability of today's intelligent agent in the multi-agent system is almost negligible compared with that of human being. This makes people wonder how close a multi-agent system can mimic a real economic world. Here we maintain that "simpler true is better than sophisticated falsehood" and with the advances of computer science it is promising that agent-based computational economics will gain a more reliable foundation. 
Restructured electricity market is a complex system. Because of the deficiency of mathematics tools and experimental method, agent-based computational economics is proposed to help with them. Although a rather young branch of economics research, the underlying methodology of agentbased economics has shown its vitality. With the help of ACE We may fortunately find the "right rules" for electricity market and solve the riddle of electricity deregulation.

\section{REFERENCES}

\section{Periodicals:}

[1] L. Tesfatsion. "Introduction to the special issue on agent-based computational economics" Journal of Economic Dynamics and Control, 25, pp.281- 293,2001

[2] Roth, Alvin E., "The Economist as Engineer: Game Theory, Experimentation, and Computation as Tools for Design Economics", Fisher-Schultz Lecture, Econometrica, 70(4), pp.1341-1378. July 2002.

[3] Bower, J., and Bunn, D.W. "A Model-based Comparison of Pool and Bilateral Market Mechanisms for Electricity Trading, " Energy Journal, Volume 21, No. 3: pp. July 2000.

[4] Derek W Bunn, Fernando S Oliveira. "Agent-based simulation: an application to the new electricity trading arrangements of England and Wales", IEEE Transactions on Evolutionary Computation, 5(5), pp.493$503,2001$.

[5] Johan Bower, Derek Bunn. "Experimental analysis of the efficiency of uniform-price versus auctions in the England and Wales electricity market ". Journal of Economic Dynamics and Control 25(3-4), Pp. 561$592,2001$.

[6] Johan Bower, Derek Bunn Claus Wattendrup. "A model-based analysis of strategic consolidation in the German electricity industry". Energy Policy, 29(12), pp.987-1005, 2001

[7] Chris S K Yeung, Ada S Y Poon, Felix F Wu. "Game theoretical multiagent modeling of coalition formation for multilateral trades ". IEEE Transaction on Power Systems, 14(3), pp.929-934, 1999.

[8] M. Wooldridge, "Agent-based software engineering", IEE Proc Software Engineering, 144(1), pp.26-37. 1997

[9] M. Wooldridge and N. R. Jennings. "Intelligent agents: theory and practice". The Knowledge Engineering Review, 10(2), pp.115-152. 1995

[10] A. E. Roth and I. Erev. "Learning in Extensive Form Games: Experimental Data and Simple Dynamic Models in the Intermediate Term", Games and Economic Behavior, 8(1), pp.164-212, 1995.

Books:

[11] Epstein, J.M., and R. Axtell, Growing Artificial Societies: Social Science from the Bottom Up, Brookings Institution Press, Massachusetts: 1996.

[12] Hayek, F.A. Individualism and Economic Order. Chicago: University Press of Chicago. [1948] (1980)

[13] Arthur, W. B., Durlauf, S. N., and Lane, D. A., eds., The economy as an evolving complex system II. Proceedings Vol. XXVII, SFI Studies in the Sciences of Complexity. Reading, MA: Addison-Wesley, Reading, MA. 1997.

Technical Reports:

[14] L. Tesfatsion. "Agent-Based Computational Economics", ISU Economics Working Paper No. 1, Revised July 2002, Available at http://www.econ.iastate.edu/tesfatsi/: 2002

[15] James Nicolaisen, Valentin Petrov, Leigh Tesfatsion, "Market power and efficiency in a computational electricity market with discriminatory double-auction pricing ", ISU Economic Report No. 52, Available at http://www.econ.iastate.edu/tesfatsi/: 2001

[16] David Newbery. "Issue and options for restructuring electricity supply industry". DAE working series, University of Cambridge. CMI working papers, Massachusetts Institute of Technology. Available at: http://www.econ.cam.ac.uk/dae/people/newbery/output-download.htm Papers from Conference Proceedings:

[17] Paul L. Joskow, "Deregulation and regulatory reform in the U.S. electric power sector", conference thesis for Brookings-AEI Conference on Deregulation in Network Industries, 1999. Available at: http://econwww.mit.edu/faculty/index.htm?prof_id=pjoskow
[18] William W. Hogan, "Electricity market restructuring: reforms of reforms", 20th Annual Conference Center for Research in Regulated Industries, 2001.

[19] Deddy Koesrindartoto and Leigh Tesfatsion, Testing the Reliability of FERC's Wholesale Power Market Platform: An Agent-Based Computational Economics Approach, 24Th USAEE/IAEE North American Conference, Washington, D.C., 2004

[20] Michael North, Guenter Conzelmann, Vladimir Koritarov, Thomas Veselka, (Argonne National Laboratory), "E-laboratories: Agent-based Modeling of electric markets ", 2002 American Power Conference, 2002, Chicago, IL, USA

[21] T Nagata, M Ohono, J Kubokawa, et al. "A multi-agent approach to unit commitment problems ". IEEE Power Engineering Society 2002 Winter Meeting. 2002

\section{BIOGRAPHIES}

Yu Shun-kun was born in Wuxi City in the People's Republic of China, on May. 1, 1963. He is now the professor at Business School, North China Electric Power University. His research interest focuses on electricity market.

Yuan Jia-hai was born in Feidong country in the People's Republic of China, on Feb. 14, 1979. He is now a Ph. D candidate at Business School, North China Electric Power University. His research interest focuses on Artificial Intelligence and simulation method in power economics. 